\title{
La escurridiza dualidad del concepto de Actitud
}

\author{
Amalio Blanco \\ Universidad Autónoma de Madrid

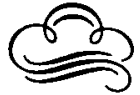

Probablemente no sea ocioso, ni casual, entablar un debate sobre la racionalidad en las Ciencias Sociales precisamente en unos momentos en los que tanto los hechos que acontecen como las actitudes de quienes los deciden parecen apuntar a que el mundo en que nos ha tocado vivir ha perdido definitivamente el juicio, quizás, y sería francamente un consuelo, como consecuencia del síndrome del milenarismo. Sea por las razones que fuere, resulta intelectualmente refrescante un artículo como el de Eduardo Crespo, cuya primera pretensión no es demostrar nada, sino plantear dudas y sugerir posibles soluciones.

La tradición más temprana y clásicamente psicosocial en ocuparse de asuntos colateralmente vinculados con la racionalidad es la liderada por Kurt Lewin y Fritz Heider, amigos y residentes en el Berlín del famoso Instituto de Psicología con el que acabó precisamente la irracionalidad y la vesania nazi. Parece que esta tradición se asienta sobre dos firmes y no siempre bien avenidas convicciones que convendría recordar en este momento: Primera, la de que lo cognitivo es primeramente una necesidad instalada en los pliegues del organismo de manera tan imperiosa como lo pueda estar el hambre y la sed. La disonancia, escribía Festinger, el discípulo más aventajado, en el primero de los capítulos de su más conocida obra, es un factor de la motivación (podemos sospechar, pero sólo eso, que se trata de una motivación con arreglo a valores), y lo es por derecho propio. Segundo, junto a ello, las teorías de la disonancia, balance, consistencia, comparación y atribución mantuvieron, prácticamente sin excepción, la idea de que cuando el sujeto busca la coherencia lo hace de acuerdo con las más estrictas leyes de la lógica formal; lo hace de manera razonada y metódica. Heider toma esto como punto de partida de una de las teorías más prolíficas en la Psicología Social, la de la atribución: el sujeto perceptor y atribuyente que todos llevamos dentro busca y utiliza la información de manera razonable; actúa como un científico ingenuo, intentando establecer una siempre compleja relación entre un efecto dado y sus posibles causas, se inquiere permanentemente sobre las razones de la conducta de la gente. Esta es una imagen, conviene no

\footnotetext{
Dirección del autor: Dpto. Psicología Básica Social y Metodología

Facultad de Psicología

Universidad Autónoma de Madrid
} 
perderlo de vista, que el propio Kelley mantendrá hasta entrada ya la década de los setenta: el atribuyente, escribirá en un trabajo de 1972, Causal schemata in the attribution process, no es un científico puro, sino un científico aplicado, una persona preocupada por la aplicación de su conocimiento de las relaciones causales al control de su ambiente, una persona en la que, a pesar de los sesgos, errores y espejismos (de cinco de ellos da cuenta en su trabajo de 1967), predomina la racionalidad y el buen sentido. Da la impresión, pues, de que la Psicología Social ha apostado por dos hipótesis que, en algún momento, bien pudieran entrar en colisión: el científico ingenuo, racional y sensato, aquel que se acoge a las reglas de la lógica formal, es el mismo que busca, por encima de todo (por encima de su propia racionalidad, si fuera preciso), el mantenimiento de la coherencia-consonancia-balance de su sistema cognitivo, es el mismo que persigue la concordia entre las creencias, opiniones y expectativas y los sentimientos y deseos que provocan. Logical thinking y wishful thinking son, en opinión de una autoridad en estos asuntos de las actitudes, William McGuire, los dos inevitables componentes de la racionalidad del hombre de la calle.

Dentro del marco de referencia en el que se plantea este debate, el de la teoría de las actitudes, existe un determinado concepto de racionalidad que, a la postre, parece que no ha acabado por jugar el papel estelar que le supuso desde el principio y en el que tantas esperanzas se depositaron: el de rector, guía y líder del comportamiento. Porque hay un detalle en toda esta historia que no conviene pasar inadvertido para entender en su justa medida la atractiva reflexión de Eduardo Crespo: varias de las teorías que sostienen ambas hipótesis son, precisa y nada casualmente, teorías clásicas del cambio de actitudes, modelos heurísticos que acuden al principio motivacional para explicar la dinámica del cambio; por ello no es de extrañar que, a la postre, la noción de actitud acabe en los brazos del afecto, del agrado/desagrado, de la homeostasis interna que, en el fondo, es más sentida que pensada. Para estas teorías, que no son las únicas que afrontan el proceso de cambio actitudinal, éste no resulta tanto de la influencia como de la comodidad y de la armonía interna, de una comodidad y armonía que trasciende, sin duda, la propia racionalidad. Por mucho que podamos seguir manteniendo que el individuo busca la concordia y la paz dentro de la algarabía de su estructura cognitiva con la ayuda de las leyes de la lógica formal, resulta evidente el papel secundario del diálogo y la argumentación en el proceso de cambio, un papel que, en algún otro momento, puede resultar primordial, tal y como ha puesto de manifiesto William McGuire en la revisión que hace para la segunda edición del Handbook de Psicología Social cuando aborda el epígrafe dedicado al orden de presentación de argumentos en el cambio actitudinal.

Pero, además de evidente, resulta comprensible la escasa importancia que se le concede al diálogo y la argumentación por cuanto la actitud, es decir, la emoción, no es primordialmente objeto de análisis y argumentación lógica, sino de sentimiento y acomodo interno. Es cuando nos instalamos, como hace el profesor Crespo, dentro de la pragmática formal y consideramos la actitud como parte de la acción comunicativa y, además de comunicativa, lingüística, cuando saltan a la vista las limitaciones del concepto tradicional y entran en juego otras consideraciones puntualmente tenidas en cuenta en el trabajo que da pie a estos comentarios. La actitud como significado evaluativo que exige un proceso de interpretación en el decurso de la acción comunicativa y lingüística, aun sin ser del todo novedoso por cuanto se sigue manteniendo como elemento central la 
evaluación, puede, en efecto, ayudarnos a superar el individualismo psicologizante que tanto necesita la Psicología Social y, sobre todo, abre las puertas a una reconsideración del inevitable fenómeno de la interacción, pero también extraña riesgos evidentes. Por ejemplo: el acto en Mead es un comportamiento previo a la conciencia, prelingüístico y, por consiguiente, precomunicativo y, sin embargo y en cierta manera, es el más acabado ejemplo de actitud. 